OPEN ACCESS

Edited by:

Marko Tkalcic,

University of Primorska, Slovenia

Reviewed by:

Mamoun Nawahdah,

Birzeit University, Palestine

Qian Janice Wang

Aarhus University, Denmark

${ }^{*}$ Correspondence:

Mailin Lemke

m.lemke@tudelft.n

Specialty section

This article was submitted to

Human-Media Interaction,

a section of the journal

Frontiers in Computer Science

Received: 19 November 2021

Accepted: 12 January 2022

Published: 02 March 2022

Citation:

Nicolau i Torra N, Lemke M and Huisman G (2022) Solo Dining at Home in the Company of ICT Devices.

Front. Comput. Sci. 4:818650

doi: 10.3389/fcomp.2022.818650

\section{Solo Dining at Home in the Company of ICT Devices}

\author{
Núria Nicolau i Torra, Mailin Lemke* and Gijs Huisman \\ Department of Human Centered Design, Delft University of Technology, Delft, Netherlands
}

The consumption of a solo meal is often subject to negative associations. Studies indicate that solo diners use information and communication technology (ICT) devices such as smartphones, to mitigate negative experiences such as boredom and loneliness, especially when dining in a public context. However, we know less about the motivation to use such devices and consequent meal experiences in a private context. For this exploratory qualitative study, we asked participants to fill out a cultural probe kit to capture their dining experience and use of ICT devices over a period of seven days. Once completed, the content was discussed with participants during a semi-structured interview. Data was analyzed using thematic analysis in a deductive and inductive form leading to four themes: (1) The experience of eating with others; (2) The use of electronic devices while eating; (3) The meaning of food; and (4) Relaxing features and influences. Participants indicated that eating alone can be a pleasurable experience that people enjoy and perceive as relaxing. ICT devices were named to play an essential part in the dining experience. The entertainment that devices provide can mitigate feelings of loneliness and uncomfortable silence when eating by oneself. We reflect on the findings and point out potential design avenues for future studies.

Keywords: eating alone, solo dining, ICT, eating behavior, qualitative, dinner, cultural probe

\section{INTRODUCTION}

The consumption of food is a biological requirement, but food and the context of eating can carry significant symbolic and cultural meaning within society (Visser, 2015; Abarca, 2021; Jönsson et al., 2021). The act of eating together is also referred to as "commensality". The term can be traced back to the medieval Latin word "commensalis" meaning as much as sharing the same table or sharing food at the same table (Jönsson et al., 2021). The act of eating together can create a sense of bonding by establishing a personal food atmosphere rather than a strictly professional one (Fischler, 2011). Eating by oneself is in contrast to commensality often perceived critically, and solo diners report on feeling stigmatized and subject to pitying (Brown et al., 2013,2020). Especially dinner can be an uncomfortable experience for people eating alone as the social expectation to eat with others seems more pronounced during this meal (Brown et al., 2020). Anecdotal reports and qualitative studies indicate that the use of information and communication technology (ICT) devices in the context of solo dining events can help to mitigate negative experiences such as boredom and even create a sense of relaxation (Toh et al., 2019; Brown et al., 2020; Lemke and Schifferstein, 2021). In the context of human-computer interaction (HCI), the use of digital technology as part of shared meals has attracted increased research interest (Niewiadomski et al., 2019; Spence et al., 2019) and different projects have investigated how technology can be created to support and recreate 
commensality in a physical and digital context (Barden et al., 2012; Khot et al., 2019; De Vries et al., 2020; Mancini et al., 2020). However, there still seems to be a lack of studies investigating the current role that commercial ICT devices play in the context of a meal. Understanding the context of use and the role that ICT devices currently play could inform the development of suitable HCI solutions. For this study, we were interested in the use of ICT devices among young adults as part of dining experiences. Among the three main meals, dinner is the most likely one consumed in the company of others (Sobal and Nelson, 2003; Holm et al., 2016; Yates and Warde, 2017) and solo diners eating in public have indicated that it is the most uncomfortable dining experience (Brown et al., 2020).

We focused on young adults due to reports indicating that ICT devices are a key component and influence in young people's lives (Aagaard, 2016; Furst et al., 2018; Allaby and Shannon, 2020). Furthermore, transitioning into a new role can be a significant point in young people's food behavior. Often this seems to be the case when people enter a college or university and make independent food choices for the first time (Marquis, 2005). During this time, the primary social influence changes from family to peers. Young people also become more responsible for and conscious of their food-related behavior (Malan et al., 2020). Furthermore, it seems that they are more likely to watch TV, use a tablet, smartphone, or laptop while eating compared to older adults (Holm et al., 2016). A potential explanation for this observed phenomenon might be that young adults and children are likely to have grown up with ICT devices, and children by the age of four already use mobile devices daily in some cases (Kabali et al., 2015). The access and penetration level of mobile devices such as the smartphone might differ between social groups and countries. Recent consumer surveys indicate that people in the Netherlands show an extremely high smartphone penetration level (93 per cent in 2019) (Steemers et al., 2017, 2019). The highest penetration level in 2017 was observed in the age group of 18-24-year-old participants (94 per cent), and nearly half of them (46 per cent in 2017 and 51 per cent in 2019) looked at their device more than fifty times a day. Social media platforms such as Facebook, Instagram, and Snapchat were reported to be used on a daily basis, with nearly 10 per cent reporting on the use of Snapchat even on an hourly basis (Steemers et al., 2017, 2019). And while these surveys leave unclear why and how the devices are used as part of the main meal, studies suggest that young adults use the device to decrease boredom and kill time (Toh et al., 2019; Allaby and Shannon, 2020). Based on these reports, we focus in this study on young adults between 18 and 30 years living by themselves or in a shared flat to examine their solo dining eating behavior.

This study explores the experience and motivation of using ICT devices during dinner among young solo diners in the home environment. For this study, we followed a human-centered design approach using a cultural probe to get a comprehensive understanding of the context of use and user experience. This article is structured as follows: We will first describe the relevant literature findings in the context of commensality and eating alone, followed by a description of the use of ICT devices during meal occasions. We will then outline the methodological details related to our study in a subsequent step, followed by the results of our thematic analysis and reflect on HCI relevant findings in our Section 5.

\section{RELATED WORK}

\subsection{Commensality and Solo Dining}

Different research disciplines have explored the concept and components of commensality using a range of methods to capture its core. It seems, though, that the term is used inconsistently and includes different conceptual constructs such as "family dinner" and "eating together" (Jönsson et al., 2021; Scander et al., 2021). The origin of the term insinuates notions of sharing a table. However, qualitative studies indicate that the symbolic dimension of commensality does not rely on sharing the same table (Fischler, 2011). Instead, places such as the couch or the bed have started to become alternative locations for gathering and sharing food. It also seems that food practices are being adjusted and transformed due to the introduction of new forms of technology such as the TV. For example, instead of gathering at a table, people report moving to the couch so they can keep on watching TV while eating (Scagliusi et al., 2016). However, while the use of ICT devices during shared meals seems to be accepted in a private context, there is a strong reluctance to use the devices while having a shared meal in a public eating context (Weber et al., 2020; Lemke and Schifferstein, 2021).

The social aspect of eating together is emphasized in many academic discussions (Pliner and Bell, 2009). Commensality can be an essential element contributing to a hedonic eating experience (Macht et al., 2005) and commensal food practices can be highly ritualized events that help to establish social relationships (Neely et al., 2014; Danesi, 2018). The shared food experience itself can be divided into multiple dimensions, including an interaction dimension (space, time, and mealrelated actions), a symbolic dimension (meaning ascribed to food and diners), a normative dimension (standards relating to food and eating context) and a material dimension (cooking and eating-related objects) (Visser, 2015; Giacoman, 2016). The details of the different dimensions differ depending on a temporal and social context, and aspects of commensality have changed throughout the centuries (Visser, 2015; Jönsson et al., 2021).

Research indicates that the context and characteristics of meal companions can significantly influence the amount and kind of food consumed. Two concepts in this context that try to explain why people tend to eat more or sometimes less when being in a group are the "social facilitation" effect and the "impression management" effect observed during shared meals (Herman, 2015). The term "impression management" describes the attempt of controlling information to influence the impression that a particular audience gets or protect one's self-image (Wayne and Liden, 1995). In the context of food consumption, observations indicate self-conscious oppression of food intake if a diner wants to leave a good impression, for example, when the meal is consumed in the company of strangers (Salvy et al., 2007; Vartanian et al., 2007; Herman, 2015). The social facilitation of eating describes the phenomenon that people tend to eat more when being in a group (Herman, 2015). It has been argued 
that ICT devices allow a form of digital companionship, which could facilitate a similar effect since the main functions used on a smartphone while eating a meal include messaging and social networking (Yong et al., 2021). This potentially evokes social facilitation of eating in the digital realm. It could also explain why people who use a smartphone while eating tend to ingest more calories (da Mata Gonçalves et al., 2019). However, further studies are needed to investigate this potential influence (La Marra et al., 2020) and clarify if social facilitation is taking place or if the use of ICT devices simply induces distraction during the meal (Lemke and Schifferstein, 2021).

While commensality is associated with numerous positive and negative aspects, eating by oneself is commonly portrayed as a negative form of eating. People can especially feel reluctant to eat out alone in public (Danesi, 2012; Takeda and Melby, 2017; Weber et al., 2020). However, it also seems that people can enjoy to eat alone (Thomas and Emond, 2017; Lemke and Schifferstein, 2021), even in a public context (Koponen and Mustonen, 2020). The increase of solo diners is often related to factors of necessity rather than choice, such as the rise of single-unit households as many people who live alone report on eating alone (Yates and Warde, 2017). Benefits associated with eating alone include being able to do other activities while eating and a certain level of freedom in terms of what and when to eat. Furthermore, people report on appreciating a lack of aspects associated with commensality such as having to participate in conversations, and practical reasons including less cleaning up (Pliner and Bell, 2009; Danesi, 2012; Takeda and Melby, 2017). However, solo dining also gives rise to disadvantages such as that the meal is not experienced as a proper meal anymore or negative experiences including loneliness. Furthermore, an absence of norms, faster eating speed and practical disadvantages have been pointed out as negative factors associated with solo eating experiences (Pliner and Bell, 2009; Danesi, 2012). Studies investigating the eating experience of the elderly also point to an increased risk of depressive symptoms among people eating alone (Kimura et al., 2012; Tani et al., 2015).

\subsection{Digital Devices During Meal Consumption}

Research exploring the experience of solo diners suggests that the use of ICT devices can mitigate negative factors such as feeling lonely. The devices also allow diners to distract themselves while eating, access entertainment or share a meal with others online (Anjani et al., 2020; Ceccaldi et al., 2020; Lemke and Schifferstein, 2021). However, it is unclear if the devices are solely used for these purposes or if their use application encompasses further domains. For example, one might question if taking photos of a nicely plated food is solely and consciously done to address the feeling of being lonely or if it can be part of one's social identity and relationship management. For example, the sharing of said food photo on social media could also help to manage one's social image and stay in touch with friends and let them be part of daily activities. It also seems that the use of the devices can differ depending on the time of day and location of eating (Lemke and Schifferstein, 2021). For example, smaller handheld devices like the smartphone are easier to use in a public context while larger devices such as laptops and TVs seem to be mainly used when eating alone at home (Koponen and Mustonen, 2020; Weber et al., 2020; Lemke and Schifferstein, 2021). However, people have also indicated that the use of technology in the context of eating a meal can distort and affect the eating experience. Diners have pointed out that digital and real-world commensality experiences are hardly comparable since the experience lacks or distorts the multi-sensory properties associated with a meal (Ceccaldi et al., 2020; Lemke and Schifferstein, 2021). Furthermore, the sense of digital companionship that ICT devices like the smartphone can create is based on the perception of closeness (emotional and spatial), trust, and preoccupation. These are essential to develop meaningful relationships but can also facilitate the experience of stress similar to human-human companionship (Carolus et al., 2019) which in turn can influence the meal perception and experience.

\subsection{Dining Across Distance}

The use of digital technology such as ICT devices during a meal has been explored in the context of HCI. Applications that allow dining across a distance are part of the research area referred to under the terms "digital commensality" and "computational commensality” (Niewiadomski et al., 2019; Spence et al., 2019). HCI examples include the development of virtual dining environments that allow diners living in different time zones to seemingly share a meal (Nawahdah and Inoue, 2013) or creating a sense of presence among distant family members (Wei et al., 2011). The use of commercial video platforms has been the basis for a social phenomenon named "Mukbang". Mukbang refers to online streamed meal experience in which the broadcast jockey commonly enjoys large quantities of high-calorie food items while interacting with the online audience. The rise in popularity of this shared online meal experience in Korea has been connected to the rise of single-person households in the region. The digital experience seems to be able to provide a sense of closeness, connection and pleasure to people dining alone (Hong and Park, 2018; Anjani et al., 2020).

\subsection{Summary}

Research in HCI has explored the development of various solutions for solo diners. It seems though that the situation is often approached from a top-down perspective where technological solutions are developed without gathering detailed insights into the lived experience of solo diners. Arguably, a deeper understanding of user requirements and contextual factors could help to develop tailored solutions. In this study, we aim to contribute to this process by exploring the experience of young solo diners. Prior research exploring the use of ICT devices as part of solo dining experiences has provided valuable insights (Weber et al., 2020; Lemke and Schifferstein, 2021). However, the studies were broad in focus (e.g., including all three meals) (Lemke and Schifferstein, 2021) or focused on the experience of dining in public (Weber et al., 2020). Furthermore, the studies used semi-structured interviews conducted once rather than collecting data and insights over a longer period. The use of methods such as cultural probes allows collecting data over a longer period and asking participants to reflect on the experience. 


\section{MATERIALS AND METHODS}

In this qualitative study, we aim to explore how young adults experience solitary dinners at home, what the role of digital technology as part of solitary dining experiences currently is and if concepts mentioned in the literature play a role in the current solo dining experiences. The aim of qualitative research is the interpretation of different data formats (e.g., linguistic or visual) to make sense of the world while maintaining its richness (Flick, 2014; Leung, 2015). We followed an interpretivist paradigm for this study rather than a positivist one. Interpretivism favors an understanding of how individuals construct meaning in their lives rather than determining generalizable causes and effects (Carminati, 2018; Gray, 2021). Based on our literature review, we were interested in the role and perception of (1) a sense of freedom while eating alone; (2) concept of privacy; (3) and the experience of being alone. We investigated the dinner experience of young solo diners by using cultural probes (Gaver et al., 1999) followed by semistructured interviews with participants. We collected the data in March 2021 in the Netherlands and Spain. Results were analyzed using thematic analysis in a deductive and inductive form to find patterns within the data (Braun and Clarke, 2006). We will describe the details of the data collection and analysis process below.

\subsection{Participants}

For this study we used a convenience and snowball sampling technique to recruit participants (Frey, 2018). We started with recruiting participants from our personal network. Participants were asked to recommend further individuals who could be interested in this study. Inclusion criteria were: Age between 18 and 29 years, eating 3-4 dinners per week alone at home, living alone or in a shared flat, and the regular use of ICT devices. Participants were informed about the purpose and structure of the study and asked to sign a consent form prior to any data collection. This study was approved by the Human Research Ethics Committee of Delft University of Technology in the Netherlands.

\subsection{Data Collection}

\subsubsection{Cultural Probe}

Conducting ethnographic studies by observing participants in their home environment can be challenging from an ethical and practical perspective. Methods such as cultural probes can help to capture and understand participant's behavior in situ that could not be collected otherwise (Gaver et al., 1999) and capture data relevant to topics which might be sensitive (Burrows et al., 2015). Participants can fill out the probes themselves and do not feel intimidated by the researcher's presence, as can be the case with traditional methods such as observations (Kjeldskov et al., 2004).

Cultural probes require participants to capture relevant information and autobiographical accounts, often using tools such as sketches, post-it notes, postcards and cameras. Prompts and instructions are provided to the participants, which guide the data collection process and makes sure that relevant information is collected (Gaver et al., 1999; Graham et al., 2007). The method of cultural probes allows minimizing the effect of observers on participants. While the method was introduced as a way to gather inspiration in the design process (Gaver et al., 1999), it can also serve as a form of inquiry into the user experience. Here, we used cultural probes to obtain data about participants, experience with ICT devices during dinner over the course of a week and used the data provided as part of the cultural probes as prompts for the follow-up interview (Carter and Mankoff, 2005).

We developed a cultural probe kit to help participants reflect on the role of ICT devices as part of the dining experience. For the development of the probe's activities and prompts, we sought inspiration from the technique Path of Expression which combines activities that focus on participants past, present and future by using-DO, MAKE, and SAY-activities (Sanders and Stappers, 2012). The probe consisted of prompts to elicit data from participants regarding their dining setup, consumed food, why and how they interacted with digital technologies, how they felt about being alone at home, and their opinion about sharing food. The cultural probe activities were designed to be filled out during seven evenings of a week.

We developed the cultural probe to be used digitally due to the COVID-19 situation. For the kit, we used the interactive website www.miro.com. The website allows users to collaborate online in an interactive environment that resembles a whiteboard and allows posting digital post-its, create drawings, and add photos and web-based images. We ran a pilot test prior to the involvement of participants and refined the activities accordingly to make sure that instructions were clear and easy to follow. For the study, we developed one kit per participant to avoid that participants could see each others' contributions. Each participant was given access to their personal Miro board as part of the introduction. We included an on-boarding session at the start of the data collection process to explain the use of the website and provide general instructions on how to proceed with the activities. Participants could ask questions about the process and use of the software during the session as well as via email once the data collection process started. The expected time to complete the daily activities was $15-20 \mathrm{~min}$ per day.

The kit consisted of an introductory part and five main elements, see Figures 1, 2. The introductory part explained how the platform could be used and asked participants for their age, gender, nationality and occupation. The first main element of the board was a resource board (Figure 1A) containing illustrations of different emotions based on videos stills of the PrEmo2 measurement tool that is used to measure emotions evoked by various stimuli, including designed objects such as cars (Laurans and Desmet, 2017). We also provided images of digital devices and logos of different video and social media platforms to help participants during the activities. The second part was a blank board reserved for personal notes and thoughts (see Figure 1B). The third part consisted of multiple panels. Each of the boards showed a food setup entry section at the top and a technology map at the bottom. As part of the food 


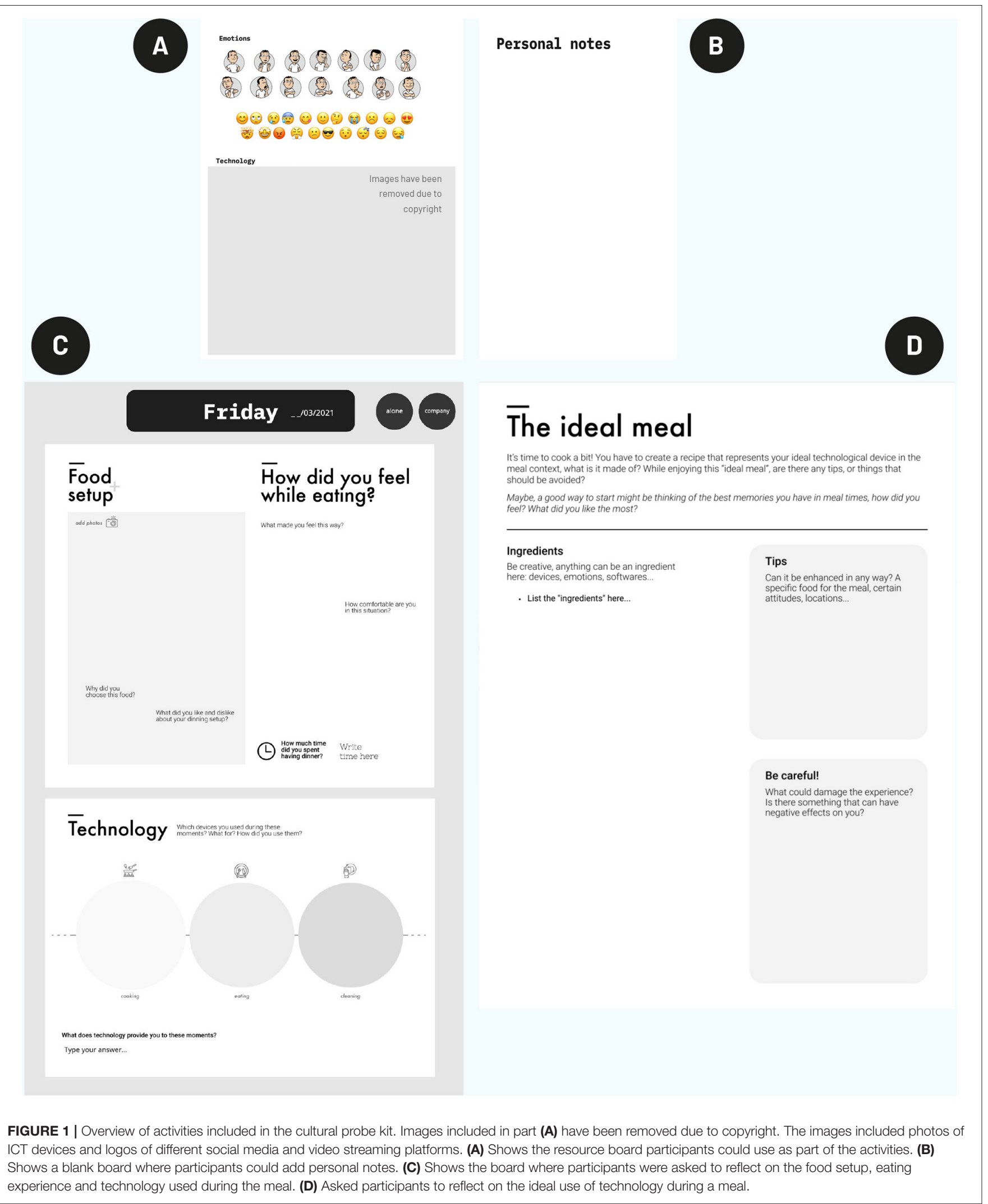

setup participants were asked to upload photos of typical food setup, explain what they were eating and why, and finally reflect on their feelings and thoughts during the meal. Participants could explain their interactions with digital devices in the technology map, including the moments of cooking, eating, and cleaning up. In this section, participants could use photos and 


\section{E}
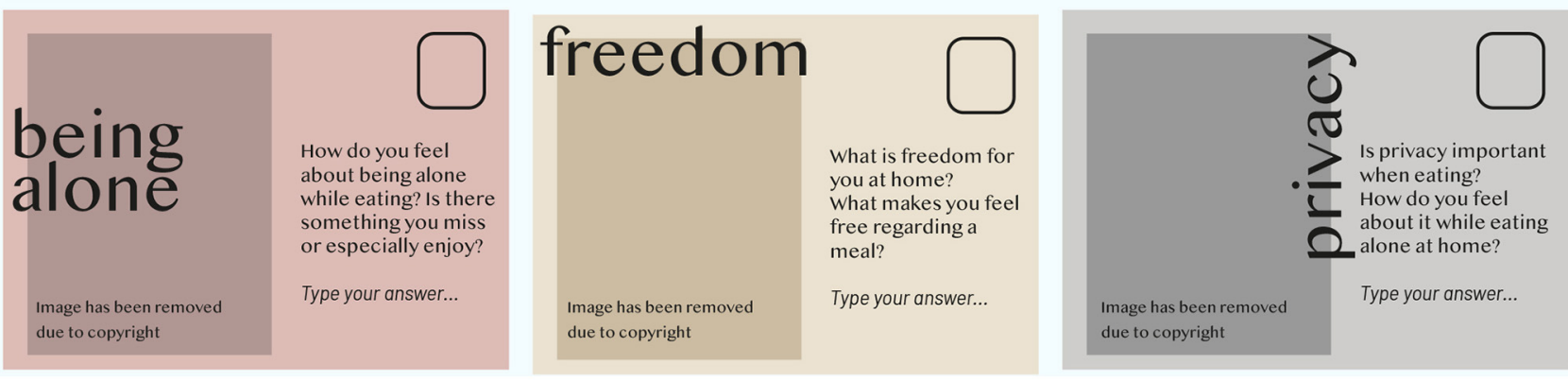

FIGURE 2 | Overview of activity (E) included in the cultural probe kit. Images included on the postcards have been removed due to copyright. The images of part (E) showed different people to illustrate the focus of the postcards, e.g., the postcard of "being alone" showed a person and a cat looking out of a window. The postcard focusing on "freedom" showed a person sitting outside using a smartphone, and the postcard about "privacy", a person sitting on a chair looking into the camera.

the provided material on the resource board. We developed seven of these elements, each of them stating the day of the entry (Monday-Sunday). Participants were also asked to indicate on the board if they ate the dinner alone and how much time they spent eating the dinner. The fourth part was an empty recipe for an ideal meal where participants could express which ingredients or technological elements could increase the experience of solo diners. This prompt was provided during the last day. The idea behind this activity was to encourage participants to reflect on their ideal meal and use of technology in this context (see Figure 1D). The fifth part included three different postcards (see Figure 2E), which asked participants about their feelings, experience and appreciation of the factors (1) being alone; (2) privacy; and (3) freedom. The topics were based on the perceived advantages and motivations of eating by oneself mentioned as part of previous studies (Danesi, 2012; Takeda and Melby, 2017; Lemke and Schifferstein, 2021). The postcard asking about the perception of freedom was provided on Tuesday. The one about being alone on Wednesday and the third one about privacy on Thursday. The postcards allowed participants to reflect and express their personal experiences from these three perspectives. However, since all the activities and prompts were outlined on one Miro board, participants also had the opportunity to fill out the different postcards at a time of their convenience. All the probe material was in!English.

The study took place over one week during March 2021, starting on a Monday and ending on a Sunday, which allowed us to understand participants' behavior and observe differences between weekdays and weekends. Participants were asked to complete the activity every day after having dinner. Every night at 9:30 p.m., an individual reminder was sent to participants who had not completed the day's activities. Participants were also encouraged to record dinner experiences that involved other people.
TABLE 1 | Overview of interview questions.

1. How relevant is food for you?

2. What do you miss the most when eating alone at home?

3. On the other hand, what do you especially enjoy in this situation?

4. (if applicable) How would you describe the experience of connecting with others through technology while cooking/having dinner?

5. Why do you need distraction while eating alone? What would happen if you did not have it?

6. What makes this moment relaxing for you?

7. Could you please elaborate on how different you felt and experienced meals when eating alone and when doing it in the company of others?

\subsubsection{Interview}

After the participants completed the cultural probes, the boards were reviewed, and individual interviews with each participant were scheduled. The goal of these interviews was to allow participants to elaborate on the content and share insights and thoughts that might have occured during the week. As part of the interview, we discussed the provided data with participants and used the images and text as prompts during the discussion. The interviews took place within one week after completing the cultural probe kit and were carried out online using the software Zoom. Interviews were audio-recorded and transcribed non-verbatim for analysis. Each participant was interviewed once, and interviews lasted between 20 and $25 \mathrm{~min}$. The format of the interview was semi-structured divided into two blocks. The first part was an unstructured open conversation focusing on the participants' data as part of the cultural probe. Before the interview, we also reviewed the kits to identify initial patterns and relevant aspects to discuss as part of the interviews. We developed a semi-structured interview guide containing seven open-ended questions based on our initial analysis (see Table 1). All the interviews were conducted in English or when 
relevant in Spanish as one of the research members is a native Spanish speaker.

\subsection{Data Analysis}

For data evaluation of the cultural probe kit and interview transcripts, we used thematic analysis to identify patterns or key themes within the data (Braun and Clarke, 2006). In an initial step, we used a deductive approach to the data coding process (Braun and Clarke, 2006), which is a top-down approach where a series of topics and concepts are brought to the data with the aim of coding and interpreting the data set. This approach leads to actively searching for parts of data according to the key topics which we defined based on our literature review. Key topics entailed (1) Eating in the company of others; (2) Entertainment; (3) Meaning of food; (4) Relaxation factors; and (5) The perception of freedom as part of the meal occasion. We coded the data consisting of the images and notes of the cultural probe and transcripts of the interviews based on those topics of interest. In a second step, we added relevant codes and themes in the process following an inductive approach. An inductive approach is a data-driven approach where codes and themes are based on the data itself rather than preconceived models and topics of interest. Our analysis was semantic by interpreting the data verbatim as originally expressed by the participants, without adding personal interpretations (Braun and Clarke, 2006). We followed the steps of (1) Familiarizing ourselves with the data and reviewing the boards and transcripts multiple times; (2) Generating initial codes by identifying relevant quotes among the data set following a deductive approach; (3) Adding additional relevant codes based on the inductive data approach; (4) Clustering codes into main themes; (5) Reviewing potential themes by verifying their relevance and seeing if they work with the coded extracts from the data set; (6) Defining and naming themes and providing a clear definition. NN developed the initial codes, sub-themes and themes. GH and ML reviewed the codes and code tree. Themes and sub-themes were refined and renamed in the process. We combined the key topic (2) Entertainment with the main theme describing the use of ICT devices while eating. We also included the key topic of (5) The perception of freedom into the theme describing the relaxing influence of ICT devices and overall perception of eating alone due to overlapping codes and sub-themes. We present the results of the analysis of the cultural probes and the interviews combined as the probes were also used as prompts during the interview.

\section{RESULTS}

Ten participants took part in the study and reported on their dinner behavior, see Tables 2, 3. Five were male $(n=5)$, and their age ranged between 23 and 29 years. All participants lived away from their home town. Eight participants lived in the Netherlands and two lived in Spain. Both countries were in a COVID-19 lockdown situation at the time of the data collection. During this time people were asked to stay and work from home to reduce transmission of the virus. Eight participants were enrolled as Master students and two participants worked full-time.

The data analysis resulted in four main themes, including (1) The experience of eating with others; (2) The use of electronic devices while eating; (3) The meaning of food; and (4) Relaxing features and influences, see Tables 4, 5 for an overview of the main themes, codes and exemplary quotes. We will outline the different themes in the following sections in detail.

\subsection{The Experience of Eating With Others}

The first theme named the experience of eating with others describes the positive and negative factors associated with the act of eating in company. Positive aspects included descriptions of eating with others as a unique and pleasurable occasion, often requiring planning and careful consideration. During a shared meal experience, conversation with others seemed to be more important than the actual food. Negative factors mentioned in the context of this theme relate to the perceived social pressure during the meal and additional effort as part of the cooking process.

Sharing the meal in the company of others, especially friends and family, was mentioned as the preferred situation by the participants. These situations were associated with positive emotions such as joy, happiness and fun. This was strongly connected to having the possibility to establish a conversation with others that allowed to share the day's experience, inquire

TABLE 2 | Demographic details of participants completing the 7-day cultural probe kit.

\begin{tabular}{|c|c|c|c|c|c|c|c|}
\hline No & Gender & Age & Living situation & Nationality & Occupation & Cultural probe response & $\begin{array}{l}\text { Days spent } \\
\text { dining alone }\end{array}$ \\
\hline P1 & Female & 25 years & Living alone & Spanish & Student, working part-time & $7 / 7$ daily reports, $3 / 3$ postcards, $1 / 1$ recipe & 4 days \\
\hline P2 & Male & 28 years & Shared household & Colombian & Working full-time & $7 / 7$ daily reports, $3 / 3$ postcards, $1 / 1$ recipe & 4 days \\
\hline P3 & Male & 25 years & Living alone & Italian & Student & $6 / 7$ daily reports, $3 / 3$ postcards, $1 / 1$ recipe & 4 days \\
\hline P4 & Female & 24 years & Living alone & Spanish & Student & $5 / 7$ daily reports, $3 / 3$ postcards, $1 / 1$ recipe & 3 days \\
\hline P5 & Female & 23 years & Living alone & Belgian & Student & $7 / 7$ daily reports, $3 / 3$ postcards, $0 / 1$ recipe & 3 days \\
\hline P6 & Male & 26 years & Shared household & Spanish & Student & $7 / 7$ daily reports, $3 / 3$ postcards, $1 / 1$ recipe & 6 days \\
\hline P7 & Female & 27 years & Living alone & Indian & Student & $7 / 7$ daily reports, $3 / 3$ postcards, $1 / 1$ recipe & 4 days \\
\hline P8 & Male & 25 years & Living alone & Spanish & Student & $7 / 7$ daily reports, $3 / 3$ postcards, $1 / 1$ recipe & 4 days \\
\hline P9 & Female & 29 years & Living alone & Spanish & Working full-time & $7 / 7$ daily reports, $2 / 3$ postcards, $0 / 1$ recipe & 5 days \\
\hline P10 & Male & 25 years & Shared household & Spanish & Student & $6 / 7$ daily reports, $3 / 3$ postcards, $1 / 1$ recipe & 2 days \\
\hline
\end{tabular}


TABLE 3 | Use of ICT devices.

No Purpose of using the ICT device when eating alone (instances mentioned/days spent eating alone)

P1 During cooking Music (3/4), Looking up recipes (1/4) During eating Browsing social media platforms (2/4), Watching TV (2/4), Face-timing family members (1/4) During cleaning Music (2/4), Calling a family member (1/4)

P2 During cooking Music (3/4) During eating Music (3/4), Watching TV (1/4) During cleaning Music (3/4)

P3 During cooking Podcast (1/4), Music (1/4), Calling a family member (2/4) During eating Podcast (1/4), Music (1/4) During cleaning Music (3/4)

P4 During cooking Podcast (1/3), Music (1/3) During eating Watching TV (1/3), Social media platform (2/3), Podcast (1/3) During cleaning Music (2/3), Podcast (1/3)

P5 During cooking Social medial platform (2/3), Texting (1/3), Timing function on the phone (3/3), Checking emails (1/3) During eating Watching TV (3/3), Social media platform (1/3) During cleaning Music (1/3), Watching TV (1/3)

P6 During cooking Watching TV (4/6) During eating Watching TV (6/6) During cleaning None

P7 During cooking Music (1/4), Watching TV (1/4) During eating Social media platform (1/4), Watching TV (4/4) During cleaning None

P8 During cooking Watching TV (2/4), Working on the computer (1/4) During eating Watching TV (3/4), Working on the computer (1/4) During cleaning Watching TV (3/4), Working on the computer (1/4)

P9 During cooking Watching TV (1/5), Listening to music (1/5), Face-timing a friend (2/5), Working on the computer (1/5) During eating Watching TV $(3 / 5)$, Working on the computer (2/5) During cleaning Face-timing a friend (1/5), Calling a friend (1/5), Watching TV (1/5), Working on the computer $(1 / 5)$

P10 During cooking Working on the computer (1/2) During eating Texting (1/2), Working on the computer (1/2) During cleaning None

about and express how people were feeling. Participants valued especially meals shared within a family as this is what they were used to. In this context, meals were described as relaxing and happy moments because of family members' established trust and comfort.

Participants stated that food often took on a secondary role in shared meal occasions and that the possibility of socializing, including having a conversation with others, was more important. Nonetheless, the setting and preparation of a meal were mentioned as essential factors in this context. People paid attention to these aspects to make the moment memorable and even impress dinner companions. Participants also described the food and the table setting to be more elaborate compared to solo dining events.

When I am with friends, we prepare things that we don't eat in our daily routines, we like to make the moment more special. P8

This increased effort also caused participants to experience it as tiring. Especially when cooking for others, participants often perceived pressure to please and provide a good meal. Socializing itself as part of a meal was also mentioned as occasionally tiring since it would require some effort and planning.
If I have a lot of dinners with friends or lunches with friends. I end up tired because of it. It takes a lot of effort to socialize. P1

As a result, most participants mentioned that they enjoyed having a balance between dinners in company and solitary dinners during the week.

\subsection{The Use of Electronic Devices While Eating}

The second theme use of electronic devices while eating relates to the way ICT devices were used as part of the solo dining occasion. This included the use for entertainment purposes, listening to music as a form of background noise, and calling other people. The devices were also used to distract, as a form of company and to break the silence. Some participants perceived the silence as giving rise to feeling lonely, while others appreciated the occasional silent meal alone.

It's because otherwise, I get a little bit stressed because if it's too silent, I think too much about everything. $P 5$ being asked while they seek distraction while eating.

Participants indicated that a personal computer is an essential element of participants' dining set. Participants also mentioned that having access to entertainment has become a need for them rather than an option when they are eating alone. This entertainment, in most cases YouTube, Netflix, or a podcast, was described as having something to focus on and to disconnect and relax. Entertainment was accessed with ICT devices while cooking as well as eating.

Music, while you're cooking is like company. So basically, it is better than to be alone and silent. P3

The use of ICT devices as a source of entertainment to create a sense of company was also reported (low prevalence of the code). Having a background sound such as music or podcast was found essential for most participants. Content accessed with the ICT devices such as videos or music facilitated feeling distracted and avoiding negative emotions and thought patterns. Moreover, a few participants highlighted the role of music to help them create a better ambience and improve their mood. Some participants explained that calling someone on the phone or through a video call was a common occurrence for them (low prevalence of the code). This enhanced the perception of being connected to others since the eating activity was shared (via video call). Nonetheless, online conversations were described as "weird" if people could not be adequately seen during the video chat. Having a conversation with more than one person was also perceived as quite challenging.

When I do video calls with my family... because it's mainly with my family. Sometimes [I do video calls] with some friends while I'm having dinner. It's really nice because it feels like we're actually doing it together like there was no barrier there we were not far from each other. P1 
TABLE 4 | Overview of themes, codes, and exemplary quotes.

\begin{tabular}{lll}
\hline Theme Code Exemplary quote & Exple
\end{tabular}

(a) The experience of $\quad$ (1) The food and table setup are more special, enjoyable and eating with others

(b) The use of electronic devices while eating done with more effort

(2) Positive feelings when sharing food with others

(3) Conversation with others is the most important part of the meal
(4) Commensal food experiences are about socializing
(5) Eating in the company of family members
(6) The pressure and effort associated with socializing

(7) A need for distraction
(8) Cooking and eating related activities

(9) Evoking the impression of company

(11) Entertainment while cooking and eating

(12) Silence as a source of discomfort

(13) Music and background sound

(14) Calling other people
It's more fun to know that if I'm putting so much effort into it someone else can also enjoy it.

Whereas the nights that you have dinner with somebody else, it's just like a highlight of the day.

Although food is important when I am with friends, I care more about the conversations we have. Food is secondary.

So it's basically about talking, arguing, laughing - it's to share a moment with others.

Eating with my family makes me happy.

If I have a lot of dinner with friends or lunches with friends, I end up tired because it. It takes a lot of effort to socialize.

It's providing me with something in the background to pay attention to.

[I] took a photo of the food and sent it to my family.

I feel like having background sound or voice while you cook or eat makes you feel like you're not alone.

I cannot eat without having entertainment in front of me or without technology.

I don't like silence in general, it makes me feel lonely.

More active music helped to make the cooking more enjoyable. A more chill playlist helped to make dinner more enjoyable.

Most of the time, if I call someone while cooking, I call my family, especially my grandmas, because they know so much about food.

TABLE 5 | Overview of themes, codes, and exemplary quotes.

\begin{tabular}{|c|c|c|}
\hline Theme & Code & Exemplary quote \\
\hline \multirow[t]{7}{*}{ (c) The meaning of food } & (15) Eating and the quality of food is important & I relate eating as you're taking care of your body. \\
\hline & $\begin{array}{l}\text { (16) Food for yourself is less important compared to food } \\
\text { eaten with others }\end{array}$ & When being alone and I am not very concerned about eating. \\
\hline & (17) Food as a reward & $\begin{array}{l}\text { When I'm alone, I always try to cook things that I love and that I } \\
\text { would enjoy. Even though sometimes it's super simple. }\end{array}$ \\
\hline & (18) Food choice is dependent on mood and energy level & If my mood is good, certainly l'll try to eat something nicer. \\
\hline & (19) Simpler dishes and faster eating speed when eating alone & I noticed that I eat faster right now when I am alone. \\
\hline & (20) Cooking is a pleasurable moment & $\begin{array}{l}\text { I love cooking and sometimes I like to experiment or try new } \\
\text { recipes that can fail, but I can do this when I am alone. }\end{array}$ \\
\hline & $\begin{array}{l}\text { (21) Solo dining offers the freedom in regards to cooking and } \\
\text { eating }\end{array}$ & $\begin{array}{l}\text { I don't have to care so much about what I eat like no one's going } \\
\text { to complain. I can have whatever I feel like having. }\end{array}$ \\
\hline $\begin{array}{l}\text { (d) Relaxing features } \\
\text { and influences of solo } \\
\text { eating }\end{array}$ & (22) Eating moments are a break from (work) routine & $\begin{array}{l}\text { It's like slowing down. It's this time where I allow myself not to be } \\
\text { productive. }\end{array}$ \\
\hline
\end{tabular}

(23) Eating alone is a moment when there is no thinking

Right now l'm more used to it. It happens a few times during the week and I actually enjoy it because it's a moment where I can just relax. I don't need to think. I don't need to be focused on anything.

(24) Eating alone requires no socializing I just need to disconnect from the world. I just need this time for me.

(25) Food can contribute to relaxation

Ending the day with a clear mind and good food - it's relaxing.

(26) Lack of food-related rules and norms when eating alone

I can be myself. Let's say, [it] is the freedom to do whatever I want.

The devices were also used for food-related tasks (lowprevalence), including looking up recipes, timing preparation steps, and taking a photo of the final dish to share with family members.

\subsection{The Meaning of Food}

The theme the meaning of food describes the different attitudes and perceptions regarding the relevance, role and form of consumed food as part of solo as well as shared eating occasions. 
The theme comprised of codes including the appreciation of food, seeing it as a form of reward and the perception of food to be less important when eating by oneself. Further codes were the dependency of food choices on one's mood and energy level, the appreciation of cooking in general and a level of freedom when cooking and eating by oneself as well as the increased speed and level of simplicity of meals consumed alone.

It seems that the perception of a meal can differ significantly among people. For example, about half of our study participants stated that food was less important when being alone compared to shared meals. On some occasions, solitary dinners were even perceived as a mere activity to nourish themselves to continue their tasks.

When being alone, I am not very concerned about eating. There are days where I just need to fill my stomach and continue with whatever I was doing before. P8

In contrast to this, some participants considered food as one of the main aspects of a meal, influenced by one's upbringing or perceived nutritional and health benefits. Participants also indicated they appreciated the act of cooking a lot, and it allowed them to relax, experiment with new recipes and experience a feeling of achievement when the meal is completed and enjoyed. Furthermore, food seems to be used as a reward to celebrate good news or a good day or to enjoy the solo dining experience.

I received some good news, so I considered having celebration food, which I don't usually have, or I can't prepare myself, because it takes too much time or is complicated. $P 8$

Food seems to be able to contribute to positive experiences, but it is also dependent on emotions. Food choices and time required to prepare it can be influenced by the mood, energy level and state of mind. When feeling stressed and tired, participants had simple food and avoided complicated preparations.

Usually, it's nicer to enjoy the meal and to take the time to cook something nice; to eat something nice as well in a nice environment. But these days since [I] have two jobs and then dinner time [...]. I just have to be very pragmatic. $P 7$

Participants indicated that solitary meals are often simpler compared to shared ones, and participants aimed for efficiency in terms of preparation time in this context. Moreover, the duration of the meals changed drastically. The average time for a meal consumed alone was 15 min whereas doing it in company was at least $1 \mathrm{~h}$. Participants also associated a certain level of freedom with the solo dining experience that allowed them to cook and eat whatever they wanted. The solo dining context allowed them to experiment with recipes and lacked social norms to eat certain food items.

\subsection{Relaxing Features and Influences}

The theme relaxing features and influences focuses on the factors and perceived benefits of eating alone in terms of being a comfortable and relaxing experience. All participants stated that eating food can be a break from one's routine and a moment during which they could stop working and disconnect from their life. Food in this context can contribute to the relaxing experience. Solo dining allowed people to stop thinking, required no socializing and was based on a certain level of freedom due to a lack of food-related norms and rules. Some participants found the prospect of a solitary meal to be relaxing and even something to look forward to.

And I would say like, when you eat with someone, it is going to be more joyful than eating alone. But eating alone is going to be more peaceful than eating with someone. $P 3$

Participants considered using ICT devices for entertainment purposes to help them relax since the devices provided distraction and allowed them to stop thinking. Participants noted that having to take part in a conversation or interaction with others while eating dinner was enjoyable during some days of the week. This was considered to be a pleasant aspect of solo dining. It was also mentioned that not having to socialize helped participants to be more calm and peaceful. This perception was often connected to being tired due to work or having a stressful day.

Well, when I'm alone, I can be relaxed and not pay much attention to anything. Just like to be there. P6

A lack of rules while eating alone and not having to behave in a determined way contributed to the perception of freedom. This freedom was also linked to other aspects by participants, such as eating whatever they wanted or eating dinner while sitting on a sofa instead of the kitchen table. The food itself was also mentioned to contribute to relaxation when it was eaten without a rush or of good quality.

\section{DISCUSSION}

In this study, we explored how young adults experience solitary dinners at home. We were interested if the benefits associated with eating alone mentioned in the literature play a role in the current solo dining experiences. We were also interested in the use of ICT devices before, during and after the meal. We used a cultural probe and semi-structured interview to gain a deep understanding of the lived experience of young solo diners.

Our participants indicated that eating with others was often preferred to eating alone since it triggered emotions such as joy and happiness and invited them to have a more elaborate dinner setup. However, participants also enjoyed eating alone, especially if they had a busy day and felt tired. Balancing commensal meals with solitary dinners was appreciated by participants as the latter facilitated a feeling of relaxation. Regarding the food, participants often looked for fast and straightforward options when eating alone, especially when feeling mentally and physically drained. Nevertheless, food as part of solo dining was also used as a reward with the potential to increase the overall mood and experience. Solo cooking and eating were signified by an absence of foodrelated norms allowing them to eat and cook whatever they felt like. 
Participants pointed out specific benefits of eating alone, including a lack of pressure and effort associated with eating as part of a group and a certain level of freedom regarding food choices. This confirms earlier studies exploring solo dining habits (Pliner and Bell, 2009; Takeda and Melby, 2017; Lemke and Schifferstein, 2021). However, solitary meals can also be associated with negative factors, including feelings of loneliness (Sobal and Nelson, 2003; Lemke and Schifferstein, 2021). Participants in our study mentioned that they used ICT devices to mitigate or avoid such negative meal components as they provide entertainment and distraction. ICT devices can also evoke a feeling of relaxation (Takeda and Melby, 2017; Lemke and Schifferstein, 2021) and our study suggests that the aspect of relaxation was one of the most enjoyable factors associated with eating by oneself. However, the aspect of relaxation when eating alone can be multi-factorial and connected to the material, interaction and normative dimension of eating. For example, the relaxing aspects of the material dimension included eating good quality food, while the relaxing influence based on the normative dimension was connected to a perceived lack of supervision relating to the way and kind of food that should be eaten.

As part of our cultural probe, we explored how ICT devices are used as part of the solo dining experience. Our results indicate that devices such as smartphones, tablets or computers are often present on solo diner's tables, and they seem to be as crucial in the dining sets as the cutlery or food itself. This observation has also been noted in the context of public dining (Weber et al., 2020). ICT devices at home are currently used during cooking, eating and cleaning up and have a strong focus on providing some form of distraction and entertainment (Lemke and Schifferstein, 2021). Research by Google suggests that ICT devices like the smartphone have become a kind of sous-chef for young people, and nearly two-thirds of people between 25 and 34 years use their smartphone or tablet to search for advice on what to make and how to prepare food properly (Cooper, 2015). In our study, few participants used the devices for such purposes. The majority of applications focused on creating a sense of company, disrupting uncomfortable moments of silence, and providing entertainment in an auditory or visual form, confirming previous findings (Toh et al., 2019; Weber et al., 2020; Lemke and Schifferstein, 2021). The devices played a role in the background (e.g., playing some music) or were a primary focus (e.g., calling people while cooking). We will reflect on potential design implications for solo dining experiences based on the findings of our study in the next section.

\subsection{Suggestions for Design Direction}

Participants in the current study generally appreciated the prospect of eating in the company of others but also indicated enjoyment of eating a meal alone. The solo dining experience can be a moment signified by a level of freedom in regards to the food eaten, including trying out new recipes (Takeda and Melby, 2017; Lemke and Schifferstein, 2021). Participants pointed out that the act of cooking is often a core element of the overall eating experience. This suggests that HCI projects could benefit from a holistic perspective on the eating as well as the cooking process. For example, the development of technology that supports people to be creative with food ingredients and preparation would acknowledge that the preparation of a meal can be associated with pleasure and is, for some people, a way to express creativity (Grimes and Harper, 2008). An example for such a potential application is Autodineur, a computergenerated guide for an exploratory eating experience, providing the user with a set of provocative instructions which disrupt the established food rituals. Autodineur gives the diner different prompts, such as grabbing four horrible food items and eating the dish while having a bath (Marsden and Giles, 2020).

A holistic perspective on increasing the user experience during the food preparation and consumption process could include creating specific items required for cooking and eating (e.g., plates or cutlery) or even the food itself. Participants in our study confirm that food can offer benefits despite its nutritional values. Food can carry great symbolic meaning (Visser, 2015), evoke pleasure and contribute to a hedonic eating experience (Macht et al., 2005). It can also elevate one's mood, as indicated in our study, which can include the nostalgic and indulging characteristics that are associated with particular food items (e.g., eating warm soup as comfort food) (Locher et al., 2005). HCI projects in this context have started to explore how technology could be used to change the role and functional elements of food as we know it (Zoran, 2019; Deng et al., 2021). Future studies are needed to explore how HCI applications could address the specific needs of solo diners. For example, many participants indicated the need for quick and straightforward dishes or preferred to eat alone when they felt physically and mentally drained.

Participants used ICT devices while eating mainly for entertainment purposes but also to stay in touch with friends and family members and take part in shared commensal experiences. The use of commercial HCI applications such as Skype, Facebook, or video platforms such as YouTube can facilitate a remote dining experience (Hong and Park, 2018; Anjani et al., 2020; Ceccaldi et al., 2020). Research in this context has also explored enabling a commensal eating experience when diners are separated by time. For example, the living cook book allows people to record and share their cooking experience with loved ones which facilitates a sense of presence and sociability (Terrenghi et al., 2007). Future studies could help determine how HCI could enable the commensal eating experience and avoid an impression of the experience to be "weird" as currently described by our participants. Some participants of our study also pointed out that socializing during a shared meal can be exhausting. Future studies are needed to explore different ways of establishing a sense of social connectedness that requires little to no verbal interaction. For example, artificial dining companions could focus on non-verbal communication when interacting with human diners (Kado et al., 2010).

It has also been pointed out that a focus in Human Food Interaction (HFI) projects is often on correcting seemingly undesirable user behavior regarding cooking, eating, and understanding food properties. Different projects in this context have tried to minimize uncertainty, distraction, inefficiency, inexperience and lack of nutritional knowledge 
(Grimes and Harper, 2008). Developing celebratory forms of technology as suggested by Grimes and Harper (2008) by taking account of food-relevant aspects such as creativity and relaxation could help develop technology for solo diners, which enriches the overall experience rather than trying to correct it. In this context, playful interaction with food could be another concept of interest for HCI (Mueller et al., 2018) as playful elements can facilitate an engagement with food and can be an established part of a culture's food tradition (Visser, 2015; Altarriba Bertran et al., 2020). Such a perspective requires challenging the normative perspective on how an ideal meal should be eaten and developing new and different ways of food consumption. In this context, design projects have started exploring solutions for solo dining specific food consumption patterns (Sebambo, 2015; Ker, 2019; Juárez Bocanegra, 2021) which could be a source of inspiration for future HCI studies.

In the context of meal consumption, it also needs to be considered that eating is a multi-sensory experience, and the relevance of the ambience (Stroebele and De Castro, 2004; Macht et al., 2005) allows to broaden the possibilities to involve technology in this context. Being a multi-sensory experience does not mean that only aspects of the food such as the color, texture or smell can influence the perception of a meal, but also the eating environment, including the light, temperature or sounds. These elements can be designed to influence the user's perception (Spence et al., 2013; Spence, 2020; Schifferstein, 2021) and/or technologically augmented (Spence and PiquerasFiszman, 2013). For example, participants in the current study indicated that the experience of silence when eating alone could sometimes evoke the impression of loneliness affecting the meal experience. Participants in our study commonly reported on using ICT devices and applications that decrease such negative experiences or provide some sort of entertainment. The development of HCI applications that take account of the multi-sensory experience of food consumption without inducing excessive distraction could offer a rich playground for HCI researchers and could even contribute to healthier food consumption. For example, by slowing the eating speed as participants indicated eating significantly faster when eating alone compared to eating in company. Research in the context of sound and eating suggests that the tempo and articulation of music can subconsciously influence the eating speed (Mathiesen et al., 2020), which could be used to promote healthier food consumption. We see the use of sound in the context of $\mathrm{HCI}$ as an area with great potential to modulate the eating experience as many participants indicated listening to music when being alone as well as when eating in company (Table 3).

\section{LIMITATION}

There are a number of potential limitations in regards to the presented study. Our focus in this study was on young adults and their dining experience in a private context. Eating alone in public might evoke different responses, and studies suggest that young adults perceive public solo dining rather negative (Sobal and Nelson, 2003). Furthermore, people who are forced to eat alone might experience it as a moment signified by loss and contributing to depressive symptoms, which can affect the overall quality of life (Kimura et al., 2012; Vesnaver et al., 2016). These factors were not mentioned in the current study, which might be due to the focus on young adults and a self-selection bias of participants as our sample potentially includes solo diners who feel relatively comfortable eating alone and talking about their experience. Research findings also indicate that the solo dining experience might differ for men and women (Takeda and Melby, 2017). Furthermore, there might be a cultural difference in the perception of how the ideal meal should be eaten. Our convenience sample included different nationalities, but we did not notice a difference in responses during the analysis process in regards to gender and cultural perception of an ideal meal. Further studies are required to explore if the factors of gender, occupation (student vs. employed), the context of living (alone vs. in a shared household) or cultural context play a role in the perception of a solo dining experience.

The study context might, furthermore, have influenced our results. The study took place in the Netherlands and Spain during a time of an extended lock-down (March 2021). Participants indicated that COVID-19 related restrictions, which required them to stay and work alone the whole week, impacted the possibility to enjoy a meal alone since the solo meal experience was seen as forced onto them rather than a deliberate choice. This perception related to eating alone but also to the use of ICT devices as some participants mentioned that due to having to sit all day in front of a computer, they would consciously try to minimize screen time while having dinner. One of the participants (see Table 2) reported on eating alone on just two days during the seven days data collection. This might have biased the results of the study as our inclusion criteria stated a minimum of three days of eating alone when we approached participants.

The results of this study also need to be interpreted in regards to the interpretivist approach and methods used. The generation of generalizable results only rarely takes place in interpretivism. For example, when developing theories using the qualitative method of grounded theory (Carminati, 2018). The results of this study should, therefore, be interpreted in regards to the present research context focusing on the experience of young adults living in Western Europe. Future studies could explore if the identified themes and codes are transferable to a different population and living context.

We used cultural probes to gain a deeper understanding of the experience of solo diners. However, the self-reported experience of participants might be biased due to the method, which increased the level of attention to the dining experience. People indicated that the activity of recording their food-related behavior made them aware of how they used ICT devices while eating, which might have caused different behavior patterns or reflections on one's behavior. For example, one participant pointed out that they realized just during the data collection process how they tended to use one fork to eat while holding 
a smartphone in the other hand. Using video observations of people's dining habits and collecting data for multiple weeks could help reveal further insights.

An important but unanswered question in this study is the potential negative implications related to the use of technology in the solo dining context. Some studies have demonstrated the adverse effects of eating in front of a screen, mainly seen as an unhealthy dietary behavior (Pearson et al., 2017). Since the attention is not focused on the food, overeating during the meal or not feeling full afterwards, eventually leading to more food consumption, could potentially become an issue. This study did not address this aspect. Instead, we focused on understanding the potential benefits of using technology during solitary meals. Despite our results revealing that technology is a great option for helping people who eat alone feel better, further research is required to identify its drawbacks fully.

\section{CONCLUSION}

Food consumption is a biological necessity, but the food itself and the way it is eaten can carry significant symbolic and cultural meaning within society. Using a cultural probe kit, we explored how young adults experience eating dinner alone. The gathered data indicates that people enjoy eating alone but often prefer eating in the company of others. Solo diners commonly used ICT devices during the meal experience to evoke a sense of company, provide entertainment, distract and share the meal experience with absent others. Solo dining was associated with multiple benefits, including a sense of freedom regarding food choices and a sense of relaxation. Further studies are needed to explore how HCI could create suitable solutions for solo diners that consider differing needs that solo diners experience.

\section{REFERENCES}

Aagaard, J. (2016). Mobile devices, interaction, and distraction: a qualitative exploration of absent presence. AI Soc. 31, 223-231. doi: 10.1007/s00146-015-0638-z

Abarca, M. E. (2021). Commensality: networks of personal, family, and community social transformation. Sociol. Rev. 69, 664-680. doi: $10.1177 / 00380261211009088$

Allaby, M., and Shannon, C. S. (2020). "I just want to keep in touch": Adolescents' experiences with leisure-related smartphone use. J. Leisure Res. 51, 245-263. doi: 10.1080/00222216.2019.1672506

Altarriba Bertran, F., Duval, J., Márquez Segura, E., Turmo Vidal, L., Chisik, Y., Juanet Casulleras, M., et al. (2020). "Chasing play potentials in food culture: learning from traditions to inspire future human-food interaction design," in Proceedings of the 2020 ACM Designing Interactive Systems Conference, 979-991. doi: 10.1145/3357236.3395575

Anjani, L., Mok, T., Tang, A., Oehlberg, L., and Boon, G. W. (2020). "Why do people watch others eat? an empirical study on the motivations and practices of mukbang viewers," in CHI 2020: Proceedings of the 2020 SIGCHI Conference on Human Factors in Computing Systems, 1-13. doi: 10.1145/3313831.3376567

Barden, P., Comber, R., Green, D., Jackson, D., Ladha, C., Bartindale, T., et al. (2012). "Telematic dinner party: designing for togetherness through play and performance," in Proceedings of the Designing Interactive Systems Conference, 38-47. doi: 10.1145/2317956.2317964

Braun, V., and Clarke, V. (2006). Using thematic analysis in psychology. Qual. Res. Psychol. 3, 77-101. doi: 10.1191/1478088706qp063oa

\section{DATA AVAILABILITY STATEMENT}

The datasets presented in this article are not readily available because the provided ethics approval excluded public dataset sharing. Requests to access the datasets should be directed to m.lemke@tudelft.nl.

\section{ETHICS STATEMENT}

This study was approved by the Human Research Ethics Committee (HREC) of Delft University of Technology. The participants provided their written informed consent to participate in this study.

\section{AUTHOR CONTRIBUTIONS}

$\mathrm{NN}, \mathrm{ML}$, and GH contributed to the conception and design of the study. NN performed the initial analysis and wrote the first draft of the manuscript. ML and GH reviewed the developed codes and themes. ML revised the manuscript and wrote sections of the manuscript. All authors contributed to manuscript revision, read, and approved the submitted version.

\section{FUNDING}

This research was funded by the Pride and Prejudice project by the 4TU federation under Grant No. 4TU-UIT-346.

\section{ACKNOWLEDGMENTS}

We would like to thank the participants who contributed their time and insights to this research.

Brown, L., Buhalis, D., and Beer, S. (2020). Dining alone: improving the experience of solo restaurant goers. Int. J. Contemp. Hospital. Manage. 32, 1347-1365. doi: 10.1108/IJCHM-06-2019-0584

Brown, L., Edwards, J., and Hartwell, H. (2013). Eating and emotion: focusing on the lunchtime meal. Brit. Food J. 115, 196-208. doi: 10.1108/00070701311302186

Burrows, A., Mitchell, V., and Nicolle, C. (2015). "Cultural probes and levels of creativity," in Proceedings of the 17th International Conference on HumanComputer Interaction with Mobile Devices and Services Adjunct, 920-923. doi: 10.1145/2786567.2794302

Carminati, L. (2018). Generalizability in qualitative research: a tale of two traditions. Qual. Health Res. 28, 2094-2101. doi: 10.1177/1049732318788379

Carolus, A., Binder, J. F., Muench, R., Schmidt, C., Schneider, F., and Buglass, S. L. (2019). Smartphones as digital companions: characterizing the relationship between users and their phones. N. Media Soc. 21, 914-938. doi: $10.1177 / 1461444818817074$

Carter, S., and Mankoff, J. (2005). "When participants do the capturing: the role of media in diary studies," in Proceedings of the SIGCHI Conference on Human Factors in Computing Systems, 899-908. doi: 10.1145/1054972.1 055098

Ceccaldi, E., Huisman, G., Volpe, G., and Mancini, M. (2020). "Guess who's coming to dinner? surveying digital commensality during Covid-19 outbreak," in Companion Publication of the 2020 International Conference on Multimodal Interaction, 317-321. doi: 10.1145/3395035.3425649

Cooper, J. (2015). Cooking Trends Among Millennials: Welcome to the Digital Kitchen. Think with Google. 
da Mata Gonçalves, R. F., de Almeida Barreto, D., Monteiro, P. I., Zangeronimo, M. G., Castelo, P. M., van der Bilt, A., et al. (2019). Smartphone use while eating increases caloric ingestion. Physiol. Behav. 204, 93-99. doi: 10.1016/j.physbeh.2019.02.021

Danesi, G. (2012). Pleasures and stress of eating alone and eating together among french and german young adults. Menu J. Eat. Hospital. Res. 1, 77-91. doi: 10.26048/5289-3f91

Danesi, G. (2018). A cross-cultural approach to eating together: practices of commensality among french, German and Spanish young adults. Soc. Sci. Inform. 57, 99-120. doi: 10.1177/0539018417744680

De Vries, R. A., Haarman, J. A., Harmsen, E. C., Heylen, D. K., and Hermens, H. J. (2020). "The sensory interactive table: exploring the social space of eating," in Proceedings of the 2020 International Conference on Multimodal Interaction (Virtual event Netherlands), 689-693. doi: 10.1145/3382507.3418866

Deng, J., Olivier, P., and Mueller, F. (2021). "Design of cyber food: beginning to understand food as computational artifact," in Extended Abstracts of the 2021 CHI Conference on Human Factors in Computing Systems (Yokohama), 1-6. doi: $10.1145 / 3411763.3451687$

Fischler, C. (2011). Commensality, society and culture. Soc. Sci. Inform. 50, 528-548. doi: 10.1177/0539018411413963

Flick, U. (ed.). (2014). "Mapping the field", in The SAGE Handbook of Qualitative Data Analysis, Vol. 170 (SAGE Publications, Inc). p. 2-18. doi: $10.4135 / 9781446282243 . n 1$

Frey, B. B. (2018). The SAGE Encyclopedia of Educational Research, Measurement, and Evaluation. London; New Delh; Singapore: Sage. doi: $10.4135 / 9781506326139$

Furst, R. T., Evans, D. N., and Roderick, N. M. (2018). Frequency of college student smartphone use: impact on classroom homework assignments. J. Technol. Behav. Sci. 3, 49-57. doi: 10.1007/s41347-017-0034-2

Gaver, B., Dunne, T., and Pacenti, E. (1999). Design: cultural probes. Interactions 6, 21-29. doi: 10.1145/291224.291235

Giacoman, C. (2016). The dimensions and role of commensality: a theoretical model drawn from the significance of communal eating among adults in Santiago, Chile. Appetite 107, 460-470. doi: 10.1016/j.appet.2016.08.116

Graham, C., Rouncefield, M., Gibbs, M., Vetere, F., and Cheverst, K. (2007). "How probes work," in Proceedings of the 19th Australasian conference on Computer-Human Interaction: Entertaining User Interfaces (Adelaide, SA), 29-37. doi: $10.1145 / 1324892.1324899$

Gray, D. E. (2021). Doing Research in the Real World. Los Angeles, CA; London; New Delhi; Singapore; Washington, DC: Sage.

Grimes, A., and Harper, R. (2008). "Celebratory technology: new directions for food research in HCI," in Proceedings of the SIGCHI Conference on Human Factors in Computing Systems (Florence), 467-476. doi: $10.1145 / 1357054.1357130$

Herman, C. P. (2015). The social facilitation of eating. A review. Appetite 86, 61-73. doi: 10.1016/j.appet.2014.09.016

Holm, L., Lauridsen, D., Lund, T. B., Gronow, J., Niva, M., and Mäkelä, J. (2016). Changes in the social context and conduct of eating in four nordic countries between 1997 and 2012. Appetite 103, 358-368. doi: 10.1016/j.appet.2016.04.034

Hong, S., and Park, S. (2018). "Internet Mukbang (foodcasting) in South Korea," in Young and Creative: Digital Technologies Empowering Children in Everyday Life (Gothenburg: Nordicom, University of Gothenburg), 111-125.

Jönsson, H., Michaud, M., and Neuman, N. (2021). What is commensality? A critical discussion of an expanding research field. Int. J. Environ. Res. Public Health 18, 1-17. doi: 10.3390/ijerph18126235

Juárez Bocanegra, N. (2021). Designing a product to enhance the experience of eating alone. An approach to enhance the solitary eating experience through design (Master's thesis). University of Twente, Enschede, Netherlands.

Kabali, H. K., Irigoyen, M. M., Nunez-Davis, R., Budacki, J. G., Mohanty, S. H., Leister, K. P., et al. (2015). Exposure and use of mobile media devices by young children. Pediatrics 136, 1044-1050. doi: 10.1542/peds.20152151

Kado, Y., Kamoda, T., Yoshiike, Y., De Silva, P. R., and Okada, M. (2010). "Sociable dining table: the effectiveness of a "Konkon" interface for reciprocal adaptation," in 2010 5th ACM/IEEE International Conference on HumanRobot Interaction (HRI) (Osaka: IEEE), 105-106. doi: 10.1145/1734454. 1734494
Ker, A. D. (2019). The Missing Dining Table. IGNANT. Available online at: https:// www.ignant.com/2016/09/14/the-missing-dining-table/ (accessed October 18, 2021).

Khot, R. A., Arza, E. S., Kurra, H., and Wang, Y. (2019). "Fobo: towards designing a robotic companion for solo dining," in Extended Abstracts of the 2019 CHI Conference on Human Factors in Computing Systems (Glasgow), 1-6. doi: $10.1145 / 3290607.3313069$

Kimura, Y., Wada, T., Okumiya, K., Ishimoto, Y., Fukutomi, E., Kasahara, Y., et al. (2012). Eating alone among community-dwelling Japanese elderly: association with depression and food diversity. J. Nutr. Health Aging 16, 728-731. doi: 10.1007/s12603-012-0067-3

Kjeldskov, J., Gibbs, M., Vetere, F., Howard, S., Pedell, S., Mecoles, K., et al. (2004). "Using cultural probes to explore mediated intimacy," in Proceedings of $\mathrm{OzCHI}$ 2004 CHISIG (Wollongong), 1-10. doi: 10.3127/ajis.v11i2.128

Koponen, S., and Mustonen, P. (2020). Eating alone, or commensality redefined? Solo dining and the aestheticization of eating (out). J. Cons. Cult. 1-19. doi: 10.1177/1469540520955219

La Marra, M., Caviglia, G., and Perrella, R. (2020). Using smartphones when eating increases caloric intake in young people: an overview of the literature. Front. Psychol. 11, 587886. doi: 10.3389/fpsyg.2020.587886

Laurans, G., and Desmet, P. M. (2017). Developing 14 animated characters for non-verbal self-report of categorical emotions. J. Design Res. 15, 214-233. doi: 10.1504/JDR.2017.089903

Lemke, M., and Schifferstein, H. N. (2021). The use of ICT devices as part of the solo eating experience. Appetite 165, 105297. doi: 10.1016/j.appet.2021.105297

Leung, L. (2015). Validity, reliability, and generalizability in qualitative research. J. Family Med. Primary Care 4, 324. doi: 10.4103/2249-4863.161306

Locher, J. L., Yoels, W. C., Maurer, D., and Van Ells, J. (2005). Comfort foods: an exploratory journey into the social and emotional significance of food. Food Foodways 13, 273-297. doi: 10.1080/07409710500334509

Macht, M., Meininger, J., and Roth, J. (2005). The pleasures of eating: a qualitative analysis. J. Happiness Stud. 6, 137-160. doi: 10.1007/s10902-005-0287-x

Malan, H., Watson, T. D., Slusser, W., Glik, D., Rowat, A. C., and Prelip, M. (2020). Challenges, opportunities, and motivators for developing and applying food literacy in a University setting: a qualitative study. J. Acad. Nutr. Diet. 120, 33-44. doi: 10.1016/j.jand.2019.06.003

Mancini, M., Niewiadomski, R., Huisman, G., Bruijnes, M., and Gallagher, C. P. (2020). "Room for one more?-introducing artificial commensal companions," in Extended Abstracts of the 2020 CHI Conference on Human Factors in Computing Systems (Honolulu), 1-8. doi: 10.1145/3334480.3383027

Marquis, M. (2005). Exploring convenience orientation as a food motivation for college students living in residence halls. Int. J. Cons. Stud. 29, 55-63. doi: 10.1111/j.1470-6431.2005.00375.x

Marsden, S., and Giles, H. J. (2020). Autodineur. Available online at: https://autodineur.neocities.org/ (accessed October 18, 2021).

Mathiesen, S. L., Mielby, L. A., Byrne, D. V., and Wang, Q. J. (2020). Music to eat by: a systematic investigation of the relative importance of tempo and articulation on eating time. Appetite 155, 104801. doi: 10.1016/j.appet.2020.104801

Mueller, F., Kari, T., Khot, R., Li, Z., Wang, Y., Mehta, Y., et al. (2018). "Towards experiencing eating as a form of play," in Proceedings of the 2018 Annual Symposium on Computer-Human Interaction in Play Companion Extended Abstracts (Melbourne), 559-567. doi: 10.1145/3270316.32 71528

Nawahdah, M., and Inoue, T. (2013). "Virtually dining together in timeshifted environment: Kizuna design," in Proceedings of the 2013 Conference on Computer Supported Cooperative Eork (San Antonio, CA), 779-788. doi: 10.1145/2441776.2441863

Neely, E., Walton, M., and Stephens, C. (2014). Young people's food practices and social relationships. A thematic synthesis. Appetite 82, 50-60. doi: 10.1016/j.appet.2014.07.005

Niewiadomski, R., Ceccaldi, E., Huisman, G., Volpe, G., and Mancini, M. (2019). Computational commensality: from theories to computational models for social food preparation and consumption in HCI. Front. Robot. AI 6, 119. doi: 10.3389/frobt.2019.00119

Pearson, N., Griffiths, P., Biddle, S. J., Johnston, J. P., McGeorge, S., and Haycraft, E. (2017). Clustering and correlates of screen-time and eating behaviours among young adolescents. BMC Public Health 17, 533. doi: 10.1186/s12889-017-4441-2 
Pliner, P., and Bell, R. (2009). "A table for one: the pain and pleasure of eating alone," in Meals in Science and Practice, ed H. L. Meiselman (Cambridge; New Delhi; Boca Raton, FL: Elsevier), 169-189. doi: 10.1533/9781845695712.4.169

Salvy, S.-J., Jarrin, D., Paluch, R., Irfan, N., and Pliner, P. (2007). Effects of social influence on eating in couples, friends and strangers. Appetite 49, 92-99. doi: 10.1016/j.appet.2006.12.004

Sanders, L., and Stappers, P. J. (2012). Convivial Toolbox: Generative Research for the Front End of Design.

Scagliusi, F. B., da Rocha Pereira, P., Unsain, R. F., and de Morais Sato, P. (2016). Eating at the table, on the couch and in bed: an exploration of different locus of commensality in the discourses of Brazilian working mothers. Appetite 103, 80-86. doi: 10.1016/j.appet.2016.03.026

Scander, H., Yngve, A., and Lennernäs Wiklund, M. (2021). Assessing commensality in research. Int. J. Environ. Res. Public Health 18, 2632. doi: 10.3390/ijerph18052632

Schifferstein, H. N. (2021). "Designing food experiences: a multisensory approach," in Transdisciplinary Case Studies on Design for Food and Sustainability, ed S. Massari (Duxford; Cambridge; Kidlington: Elsevier), 115-130. doi: 10.1016/B978-0-12-817821-8.00015-1

Sebambo, K. (2015). Eating Alone Is Normal and This Design Makes It More Comfortable. Design Indaba. Available onlibe at: https://www.designindaba.com/articles/creative-work/eating-alonenormal-and-design-makes-it-more-comfortable (accessed October 18, 2021).

Sobal, J., and Nelson, M. K. (2003). Commensal eating patterns: a community study. Appetite 41, 181-190. doi: 10.1016/S0195-6663(03)00078-3

Spence, C. (2020). Multisensory flavour perception: blending, mixing, fusion, and pairing within and between the senses. Foods 9, 407. doi: 10.3390/foods 9040407

Spence, C., Hobkinson, C., Gallace, A., and Fiszman, B. P. (2013). A touch of gastronomy. Flavour 2, 1-15. doi: 10.1186/2044-7248-2-14

Spence, C., Mancini, M., and Huisman, G. (2019). Digital commensality: eating and drinking in the company of technology. Front. Psychol. 10, 2252. doi: 10.3389/fpsyg.2019.02252

Spence, C., and Piqueras-Fiszman, B. (2013). Technology at the dining table. Flavour 2, 1-13. doi: 10.1186/2044-7248-2-16

Steemers, P., Beijn, M., Reuser, D., Gaykema, R., Bookholt, E., van Veen, J., et al. (2017). Deloitte Global Mobile Consumer Survey 2017: The Netherlands.

Steemers, P., Beijn, M., van Veen, J., Boer, R., Houwers, T., Niemeijer, M., et al. (2019). Deloitte Global Mobile Consumer Survey 2019: The Netherlands.

Stroebele, N., and De Castro, J. M. (2004). Effect of ambience on food intake and food choice. Nutrition 20, 821-838. doi: 10.1016/j.nut.2004. 05.012

Takeda, W., and Melby, M. K. (2017). Spatial, temporal, and health associations of eating alone: a cross-cultural analysis of young adults in urban Australia and Japan. Appetite 118, 149-160. doi: 10.1016/j.appet.2017. 08.013

Tani, Y., Sasaki, Y., Haseda, M., Kondo, K., and Kondo, N. (2015). Eating alone and depression in older men and women by cohabitation status: the jages longitudinal survey. Age Ageing 44, 1019-1026. doi: 10.1093/ageing/ afv145

Terrenghi, L., Hilliges, O., and Butz, A. (2007). Kitchen stories: sharing recipes with the living cookbook. Pers. Ubiquit. Comput. 11, 409-414. doi: 10.1007/s00779-006-0079-2
Thomas, N., and Emond, R. (2017). Living alone but eating together: exploring lunch clubs as a dining out experience. Appetite 119, 34-40. doi: $10.1016 /$ j.appet.2017.03.003

Toh, S. H., Howie, E. K., Coenen, P., and Straker, L. M. (2019). "From the moment I wake up I will use it ... every day, very hour": a qualitative study on the patterns of adolescents' mobile touch screen device use from adolescent and parent perspectives. BMC Pediatr. 19, 30. doi: 10.1186/s12887-019-1399-5

Vartanian, L. R., Herman, C. P., and Polivy, J. (2007). Consumption stereotypes and impression management: how you are what you eat. Appetite 48, 265-277. doi: 10.1016/j.appet.2006.10.008

Vesnaver, E., Keller, H. H., Sutherland, O., Maitland, S. B., and Locher, J. L. (2016). Alone at the table: food behavior and the loss of commensality in widowhood. J. Gerontol. Ser. B Psychol. Sci. Soc. Sci. 71, 1059-1069. doi: 10.1093/geronb/gbv103

Visser, M. (2015). The Rituals of Dinner: The Origins, Evolution, Eccentricities, and Meaning of Table Manners. Penguin Books.

Wayne, S. J., and Liden, R. C. (1995). Effects of impression management on performance ratings: a longitudinal study. Acad. Manage. J. 38, 232-260. doi: $10.5465 / 256734$

Weber, P., Engelbutzeder, P., and Ludwig, T. (2020). “"Always on the table": revealing smartphone usages in everyday eating out situations," in Proceedings of the 11th Nordic Conference on Human-Computer Interaction: Shaping Experiences, Shaping Society (Tallinn), 1-13. doi: 10.1145/3419249.3420150

Wei, J., Wang, X., Peiris, R. L., Choi, Y., Martinez, X. R., Tache, R., et al. (2011). "Codine: an interactive multi-sensory system for remote dining," in Proceedings of the 13th International Conference on Ubiquitous Computing (Beijing), 21-30. doi: $10.1145 / 2030112.2030116$

Yates, L., and Warde, A. (2017). Eating together and eating alone: meal arrangements in british households. Brit. J. Sociol. 68, 97-118. doi: 10.1111/1468-4446.12231

Yong, J. Y., Tong, E. M., and Liu, J. C. (2021). Meal-time smartphone use in an obesogenic environment: two longitudinal observational studies. JMIR mHealth uHealth 9, e22929. doi: 10.2196/22929

Zoran, A. (2019). Cooking with computers: the vision of digital gastronomy. Proc. IEEE 107, 1467-1473. doi: 10.1109/JPROC.2019.2925262

Conflict of Interest: The authors declare that the research was conducted in the absence of any commercial or financial relationships that could be construed as a potential conflict of interest.

Publisher's Note: All claims expressed in this article are solely those of the authors and do not necessarily represent those of their affiliated organizations, or those of the publisher, the editors and the reviewers. Any product that may be evaluated in this article, or claim that may be made by its manufacturer, is not guaranteed or endorsed by the publisher.

Copyright (c) 2022 Nicolau i Torra, Lemke and Huisman. This is an open-access article distributed under the terms of the Creative Commons Attribution License (CC $B Y)$. The use, distribution or reproduction in other forums is permitted, provided the original author(s) and the copyright owner(s) are credited and that the original publication in this journal is cited, in accordance with accepted academic practice. No use, distribution or reproduction is permitted which does not comply with these terms. 